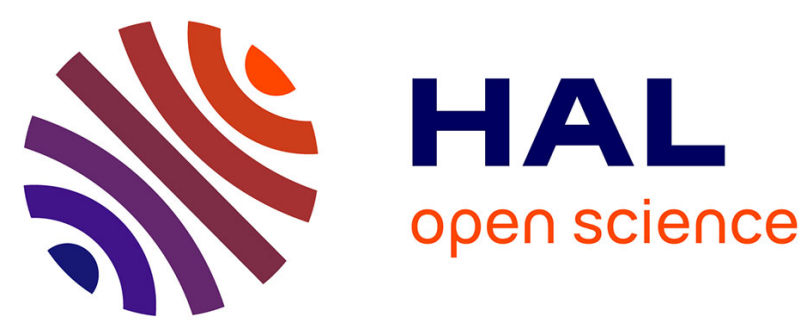

\title{
Electromagnetic pulse-induced acoustic testing and the pulsed guided wave propagation in composite/metal adhesive bonding specimens
}

Hongjun Sun, Hiroyuki Kosukegawa, Toshiyuki Takagi, Tetsuya Uchimoto, Mitsuo Hashimoto, Naoki Takeshita

\section{To cite this version:}

Hongjun Sun, Hiroyuki Kosukegawa, Toshiyuki Takagi, Tetsuya Uchimoto, Mitsuo Hashimoto, et al.. Electromagnetic pulse-induced acoustic testing and the pulsed guided wave propagation in composite/metal adhesive bonding specimens. Composites Science and Technology, 2021, 201, pp.108499. 10.1016/j.compscitech.2020.108499 . hal-03265511

\section{HAL Id: hal-03265511 \\ https://hal.science/hal-03265511}

Submitted on 21 Jun 2021

HAL is a multi-disciplinary open access archive for the deposit and dissemination of scientific research documents, whether they are published or not. The documents may come from teaching and research institutions in France or abroad, or from public or private research centers.
L'archive ouverte pluridisciplinaire HAL, est destinée au dépôt et à la diffusion de documents scientifiques de niveau recherche, publiés ou non, émanant des établissements d'enseignement et de recherche français ou étrangers, des laboratoires publics ou privés. 


\title{
Electromagnetic pulse-induced acoustic testing and the pulsed
}

\section{guided wave propagation in composite/metal adhesive}

\section{bonding specimens}

\author{
Hongjun Sun, ${ }^{\mathrm{a}, \mathrm{b}}$ Hiroyuki Kosukegawa, ${ }^{\mathrm{a}}$ Toshiyuki Takagi, ${ }^{\mathrm{a}, \mathrm{c}, \mathrm{d}, \mathrm{e} *}$ Tetsuya Uchimoto, ${ }^{\mathrm{a}, \mathrm{d}, \mathrm{e}}$ \\ Mitsuo Hashimoto, ${ }^{\mathrm{a}}$ and Naoki Takeshita ${ }^{\mathrm{a}, \mathrm{f}}$ \\ anstitute of Fluid Science, Tohoku University, Sendai, Japan \\ ${ }^{\mathrm{b}}$ Instrumentation Technology Research Section, Production Systems Research Laboratory, Technical \\ Development Group, Kobe Steel, Ltd., Kobe, Japan \\ 'Tohoku Forum for Creativity, Organization for Research Promotion, Tohoku University, Sendai, Japan \\ ${ }^{\mathrm{d}}$ Center for Fundamental Research on Nuclear Decommissioning, Tohoku University, Sendai, Japan \\ eELyTMaX UMI 3757 CNRS-Université de Lyon-Tohoku University, International Joint Unit, Tohoku \\ University, Sendai, Japan \\ ${ }^{\mathrm{f}}$ Graduate School of Engineering, Tohoku University, Sendai, Japan
}

\section{A B S T R A C T}

Materials composed of metals and plastic composites joined through adhesive bonding are being increasingly used. However, debonding of such materials may occur during manufacture or use. Nondestructive testing of adhesive bonding structures is required to evaluate their debonding. Herein, electromagnetic pulse-induced acoustic testing (EPAT) was used to detect debonding at the adhesive joint in plastic composite/metal specimens. EPAT uses a pulsed excitation current to generate guided waves in a specimen to detect debonding without contact, which makes it suitable for testing from the plastic composite side. Simulations were performed to analyze acrylic/aluminum (Al) and carbon fiber-reinforced plastic (CFRP)/Al specimens. The results showed that the Lorentz force in the $z$ direction was the dominant mechanism in the generation of guided waves, and mainly the A0-mode Lamb wave was excited. The simulation and experimental results revealed that for specimens where the mechanical parameters of the plastic composite layer differed greatly from those of the metal, such as the acrylic/Al specimen, debonding

*Corresponding author, Tel.: +81-22-217-6094; E-mail address: toshiyuki.takagi.d4@tohoku.ac.jp. 
could only be detected directly above debonding. Therefore, it is necessary to evaluate the debonding position by scanning the receiver sensor. Conversely, for specimens with reasonably similar mechanical parameters of the plastic composite and metal layers, like the CFRP/Al specimen, the debonding position could be evaluated by scanning the receiver sensor or excitation coil.

Keywords: Electromagnetic pulse-induced acoustic testing; Multi-material; Adhesive bonding; Guided wave; Non-destructive testing.

\section{Introduction}

The development of materials is accompanied by the progress of human civilization. It can be said that the use of metals, represented by steel, led to modern civilized society. Metals are the most widely used structural materials in bridges, petroleum pipelines, and other infrastructure, as well as in aircraft, automobiles, and other vehicles. Metals are widely used in structures because of their excellent properties such as high strength, high rigidity, and good ductility. In addition, metal production and processing technology has been greatly developed [1] alongside the use of metals, which has further promoted their wider application. Nevertheless, with the advance of materials technology and the requirements of energy conservation and environmental protection, plastic composite materials have been increasingly used in recent years. For example, acrylic plastic can be used in non-critical automotive and building structural parts. Carbon fiber-reinforced plastic (CFRP) is used in important components of aircraft and automobiles [2]. Recently, with the development of hydrogen vehicles, hydrogen tanks made of CFRP have been developed because of their light weight. Such hydrogen tanks have passed quality verification and been commercialized in the USA, Europe, and Japan [3]. Plastics have the advantages of lower density and higher corrosion resistance compared with those of conventional metals. In addition, composite materials such as CFRP also possess features such as high specific strength and specific stiffness. However, for complex force-transmitting structures, the structural design of composite materials is complicated [4]. Because the excellent mechanical properties of composite materials mainly originate from fibers, it is difficult to achieve excellent mechanical properties in all three-dimensional directions [5]. In addition, composite materials are easily damaged by impulsive loads [6]. Although hydrogen tanks made of CFRP are light weight, they have permeation problems and are expensive [7]. Therefore, although this type of hydrogen tank is suitable for use in hydrogen vehicles, it is not appropriate for long-term storage of high 
pressure hydrogen gas. A feasible solution to these problems is to use metal materials and plastic composite materials together to combine their respective advantages. These technique is often called "multi-material."

Adhesive bonding and mechanical fastening are common methods to join metals and plastic composites [8]. Mechanical fastening entails the use of rivets or other tools to fix multiple components together. Fastenings damage both the metal and plastic composite, and introduce problems associated with stress concentration [9], which are more serious in the composite than in the metal [10]. Adhesive bonding requires no additional machining and does not damage the materials. In addition, adhesive bonding can decrease the number of components in a structure [11]. For example, hydrogen tanks with a metal lining and composite wrapping are used at hydrogen stations to store high pressure hydrogen gas. The metal lining and composite wrapping of this type of hydrogen tank are bonded together by adhesive. The main problem of adhesive bonding is that debonding may occur during manufacture or use [12-15]. Debonding affects the service life of structures and could lead to serious accidents if not properly managed. Therefore, periodic non-destructive testing (NDT) of adhesive bonding structures is required to assess their debonding [16, 17, $18]$.

Various NDT methods have been developed for debonding detection. Radiographic testing [19] can intuitively observe the position and extent of debonding. However, it is time-consuming, expensive, and carries a risk of radiation exposure. Bulk wave ultrasonic testing [20, 21] can detect debonding but it is slow and inefficient. In addition, for thick composite materials, it is difficult to obtain sufficiently strong echo waves. Eddy current testing [22] and infrared thermography [23, 24] can quickly inspect adhesive bonding specimens without contact; however, they are mainly used for detection near the specimen surface. Ultrasonic guided wave methods have been proposed for NDT of adhesive bonding in both composites and metals $[25,26]$. An advantage of guided wave detection is that a large detection area can be quickly assessed. Guided wave testing is usually performed on plate specimens, so the guided waves are mainly Lamb waves. For specimens with circular cross sections such as hydrogen tanks or pipes, the guided waves that propagate along the circumferential or spiral direction of the pipe wall can be regarded similar to the Lamb wave modes that propagate along with a plate $[27,28]$. Therefore, specimens with circular cross sections can be evaluated by similar Lamb wave testing methods to those suitable for plate specimens.

Piezoelectric transducers are commonly used for guided wave generation. However, they require acoustic impedance matching and a coupling medium to guide the ultrasonic waves into the material, which is 
inconvenient for field application. Laser beams can also be used to excite ultrasonic guided waves [29, 30] without contact. However, laser generation devices are expensive and large. Electromagnetic acoustic transducers (EMATs) $[31,32,33]$ are attractive devices for guided wave generation. An EMAT is constructed of permanent magnets and coils, so it has a simple structure and low cost. In an EMAT, ultrasonic waves are generated by the dynamic electromagnetic force that results from the interaction between the static magnetic field from the permanent magnets and the eddy current (dynamic magnetic field) from the coils subjected to alternating current (AC). Therefore, an EMAT is a type of non-contact ultrasonic transducer. However, the principle of EMATs mean that they are only suitable for metal specimens. For the plastic composite/metal adhesive bonding specimens studied here, EMAT can generate guided waves from the metal side. However, for many practical situations, such as a hydrogen tank with a metal lining and composite wrapping, if the guided waves are excited from the metal side, the system becomes inconvenient to operate and may even damage to the surface of the metal material. For these situations, we proposed the use of electromagnetic pulse-induced acoustic testing (EPAT) [34] to generate guided waves in plastic composite/metal adhesive bonding specimens. EPAT can excite an electromagnetic field from the outside of a plastic composite material without contact, thereby directly generating sound waves on the metal adhered to the plastic composite.

In this paper, we first introduce the principle of EPAT. Then, the characteristics of EPAT are analyzed by finite element (FE) simulations. The results of the FE simulations are verified by experiments. A method to detect debonding in plastic composite/metal adhesive bonding specimens is proposed.

\section{Principle of electromagnetic pulse-induced acoustic testing}

Figure 1 shows the principle of EPAT. The transmitter probe is an excitation coil. When a pulsed current is passed through the excitation coil, a pulsed magnetic field is generated around the excitation coil. The pulsed magnetic field induces a pulsed eddy current in a conductor. If the upper layer of the specimen is insulating, such as acrylic, the eddy current is only generated in the metal lower layer of the specimen. If the upper layer is a conductor such as carbon fibers in CFRP, the eddy current is generated in both the upper and lower layers $[35,36]$. However, the conductivity of composite materials such as CFRP is much lower than that of metals; therefore, the eddy current in the former is much weaker than that in the latter. 


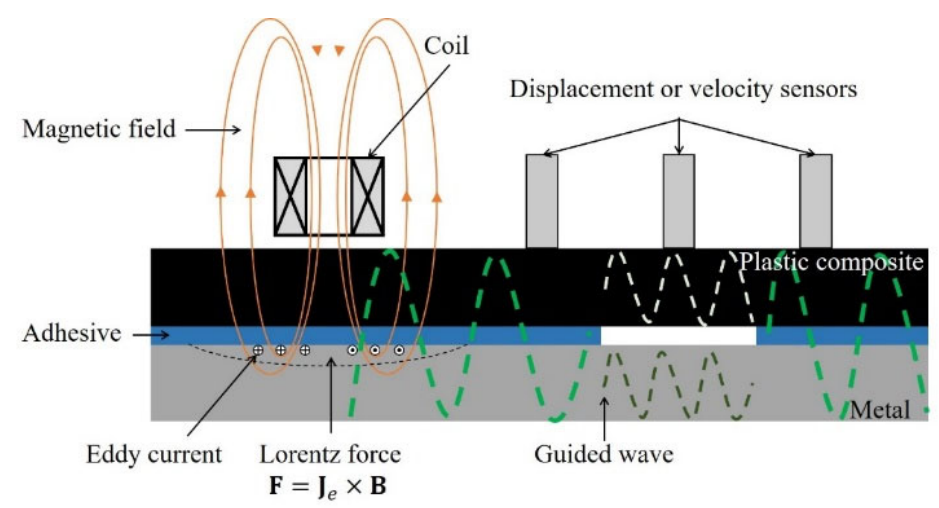

Fig. 1. Principle of electromagnetic pulse-induced acoustic testing (EPAT).

The mechanism of the excitation of guided waves in EPAT is similar to that of an EMAT. The guided wave is driven by electromagnetic forces. The electromagnetic forces arise from the interaction between the magnetic field and eddy current. In non-ferromagnetic metals, because there are no magnetic domains, the electromagnetic force is solely the Lorentz force. In ferromagnetic metals, because of the effect of magnetic domains, the electromagnetic forces include the Lorentz force and magnetostrictive force. The magnetostrictive force is highly non-linear and its properties depend on the magnetic properties of the material. In this paper, aluminum ( $\mathrm{Al})$, which is a non-ferromagnetic metal, is used as the lower layer of the bonded specimens. Therefore, only the Lorentz force was considered. The Lorentz force is usually expressed as the Lorentz force density $\mathbf{F}$.

$$
\mathbf{F}=\mathbf{J}_{e} \times \mathbf{B},
$$

where, $\mathbf{J}_{e}$ is the eddy current in the metal and $\mathbf{B}$ is the magnetic flux density. The electromagnetic force is dynamic, so it generates a guided wave in the specimen that propagates along with the specimen.

When the guided wave passed through a debonded region, it passed through the composite and metal respectively (Fig. 1). The interaction between the guided wave and debonded region will affect the propagation of the guided wave. Thus, debonding and its location can be evaluated by the changes in the propagation of the guided wave using displacement or velocity sensors at several measurement points.

\section{EPAT and its simulation}

\subsection{FE simulations}

The FE simulation of EPAT involved two steps, dynamic magnetic field (eddy current) simulation and elastic mechanics (elastic wave propagation) simulation. These two simulation steps were connected through the transmittance mechanism of electromagnetic force. 
Three-dimensional (3D) FE simulations were performed using COMSOL Multiphysics 5.4 software. The magnetic field interface in the AC/DC module was used to calculate the dynamic magnetic field and eddy current and the solid mechanics interface in the structural mechanics module was used to calculate the elastic wave propagation. The Lorentz force was defined in the variables. In this paper, two types of specimens, acrylic/Al and CFRP/Al, were evaluated. For each type of specimen, one without debonding and one with debonding were calculated. For the convenience of calculations and discussion, the CFRP used here was unidirectional CFRP. The specimen and excitation coil are shown is Fig. 2. The thickness of the acrylic or CFRP layer was $4 \mathrm{~mm}$ and the Al layer was $6 \mathrm{~mm}$ thick. All specimens were square plates with a side length of $400 \mathrm{~mm}$. The inner and outer diameters of the excitation coil were 26 and $32 \mathrm{~mm}$, respectively, and its height was $11 \mathrm{~mm}$. The center of the coil was located at $-100 \mathrm{~mm}$ on the $x$ axis. The distance between the excitation coil and the upper surface of the specimen was $1 \mathrm{~mm}$. To calculate the magnetic field, an air domain of $120 \times 120 \times 100 \mathrm{~mm}$ surrounded the coil and part of the specimen. The center of the air domain was at $(-100 \mathrm{~mm}, 0 \mathrm{~mm}, 30 \mathrm{~mm})$ in the coordinate system shown in Fig. 2. The fiber direction of CFRP was along the $x$-axis. The debonded region of the specimens with debonding was set in the position depicted in Fig. 2. For the CFRP specimen, the debonding was along the fiber direction. In this study, the adhesive layer was not included. Therefore, debonding was simulated by replacing the CFRP or acrylic material at the debonding position with an air layer. For the convenience of meshing, the thickness of the air layer is set to $0.5 \mathrm{~mm}$. In fact, the thickness of the adhesive layer in plastic composite/metal adhesive bonding specimens is generally about 0.05 to $0.1 \mathrm{~mm}$; therefore, it was reasonable to omit the adhesive layer from the simulations. Because the thickness of the air layer used here to represent debonding is much larger than the actual thickness of the adhesive layer, our simulations differ from the actual situation. However, because the purpose of the simulations in this study was to analyze the effect of debonding on the guided wave propagation without quantitative comparison, the settings used here can be considered reasonable. 


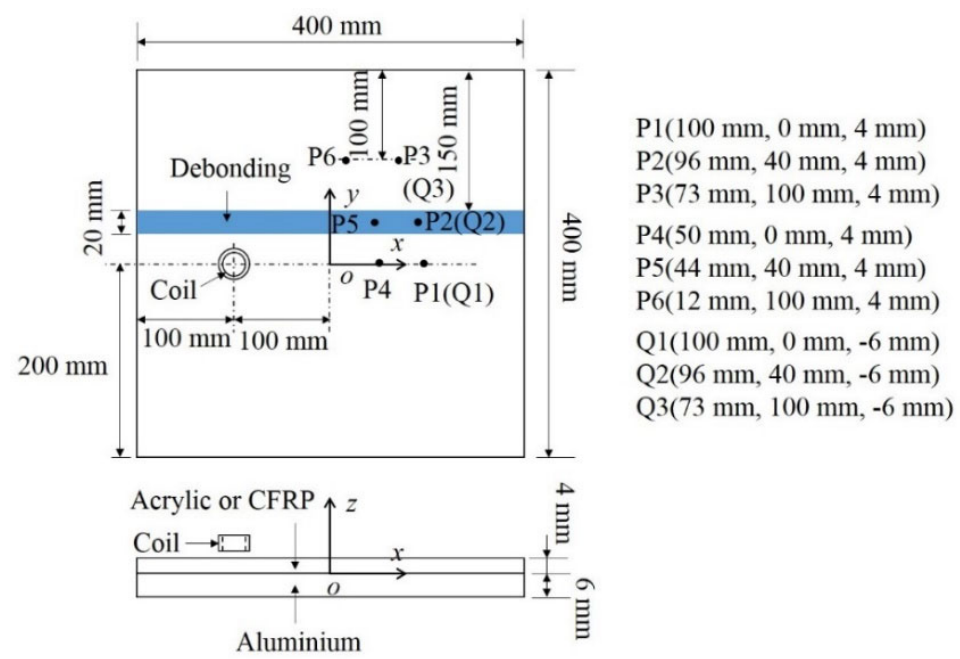

Fig. 2. Schematics showing top (upper) and cross-sectional (lower) views of a specimen and excitation coil used in this study.

The mesh division should consider both the eddy current simulation and elastic wave propagation simulation. For the part of the specimen that only needs elastic wave propagation, only the wavelength of the elastic wave needs to be considered. Because the pulsed excitation current contains a wide range of frequency components, the components with stronger amplitudes need to be considered. The excitation current curve in this simulation is shown in Fig. 3, which was obtained by the Gaussian curve fitting of the excitation current in the experiments described later. In this study, only the frequency components below $50 \mathrm{kHz}$ were considered. Therefore, the maximum size of the mesh was $3 \mathrm{~mm}$. For the part of the specimen that requires eddy current simulation, the skin effect needs to be considered. On the upper surface of the metal, the finer the mesh, the more likely it is to accurately capture the eddy current distribution. However, considering that small meshes lead to increased mesh number and a rapid increase in degrees of freedom, small meshes are difficult to implement. In addition, considering the elastic wave propagation simulation, a small mesh also represents a small time step. Therefore, the Al specimen in the eddy current simulations was divided into six layers with gradually changing thickness in the depth direction. The thickness of the uppermost layer was about $0.5 \mathrm{~mm}$. Each of the models was divided into 316342 elements. The material parameters used for the simulations are listed in Table 1. It should be noted that the conductivities of acrylic and CFRP were set as 1 and $5000 \mathrm{~S} / \mathrm{m}$, respectively, for convenience, and because they are much lower than that of $\mathrm{Al}$, they can almost be ignored. 


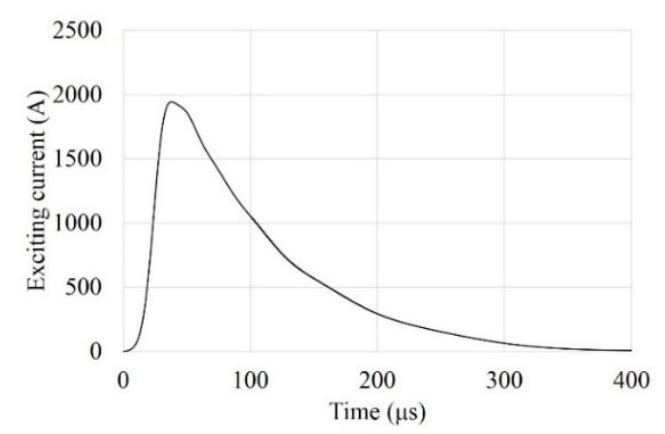

Fig. 3. Pulsed current signal used in simulations.

Table 1 Material parameters used in simulations. The numbers in round brackets in CFRP respectively indicate the values in the $\mathrm{x}, \mathrm{y}$, and $\mathrm{z}$ directions in that order.

\begin{tabular}{|l|l|l|l|}
\hline Material & $\mathrm{Al}$ & Acrylic & CFRP (unidirectional) \\
\hline Conductivity & $3.77 \times 10^{7} \mathrm{~S} / \mathrm{m}$ & $1 \mathrm{~S} / \mathrm{m}$ & $5000 \mathrm{~S} / \mathrm{m}$ (as isotropic) \\
\hline Relative permeability & 1 & 1 & 1 \\
\hline Relative permittivity & 1 & 4 & 3 \\
\hline Density & $2700 \mathrm{~kg} / \mathrm{m}^{3}$ & $1190 \mathrm{~kg} / \mathrm{m}^{3}$ & $1560 \mathrm{~kg} / \mathrm{m}^{3}$ \\
\hline Young's modulus & $70 \mathrm{GPa}$ & $3.9 \mathrm{GPa}$ & $(127 \mathrm{GPa}, 8.3 \mathrm{GPa}, 8.3 \mathrm{GPa})$ \\
\hline Poisson's ratio & 0.33 & 0.35 & $(0.35,0.25,0.35)$ \\
\hline Shear modulus & - & - & $(47 \mathrm{GPa}, 3.3 \mathrm{GPa}, 47 \mathrm{GPa})$ \\
\hline
\end{tabular}

\subsection{Results and discussion}

Figure 4 shows the calculated eddy current distribution in the specimen viewed along the $y$ direction. A typical skin effect, which is reflected on the upper surface of the metal layer, was observed and the range affected by the eddy current increased over time. In addition, because of the presence of the acrylic layer, the distance between the excitation coil and metal surface was large, which increased the distribution range of eddy current in the horizontal plane of the specimen; however, the strongest eddy current was concentrated directly below the excitation coil. Figure 5 displays the Lorentz force distribution in the specimen viewed along the $y$ direction. In this figure, there is no Lorentz force in the $y$ direction because the eddy current flows along the $y$ direction. The Lorentz force is affected by the eddy current, and its distribution is more concentrated on the upper surface of the metal layer than in the case for the eddy current. This is because according to Eq. (1), the Lorentz force is generated by the eddy current and dynamic 
magnetic field, which exacerbates the concentration of the Lorentz force on the upper surface of the metal layer. Figure 5 reveals that the Lorentz force in the $z$ direction is always much larger than in the $x$ direction. Thus, the Lorentz force in the $z$ direction is the dominant mechanism in the generation of elastic waves. The Lorentz force in the $z$ direction always points away from the excitation coil. This behavior is similar to that in a ball impact experiment. The pulsed force in a ball impact experiment acts on the surface of the whole specimen (here it is the acrylic layer), whereas the pulsed force in EPAT acts on the surface of the metal layer. Therefore, the A0-mode Lamb wave is mainly excited in EPAT.
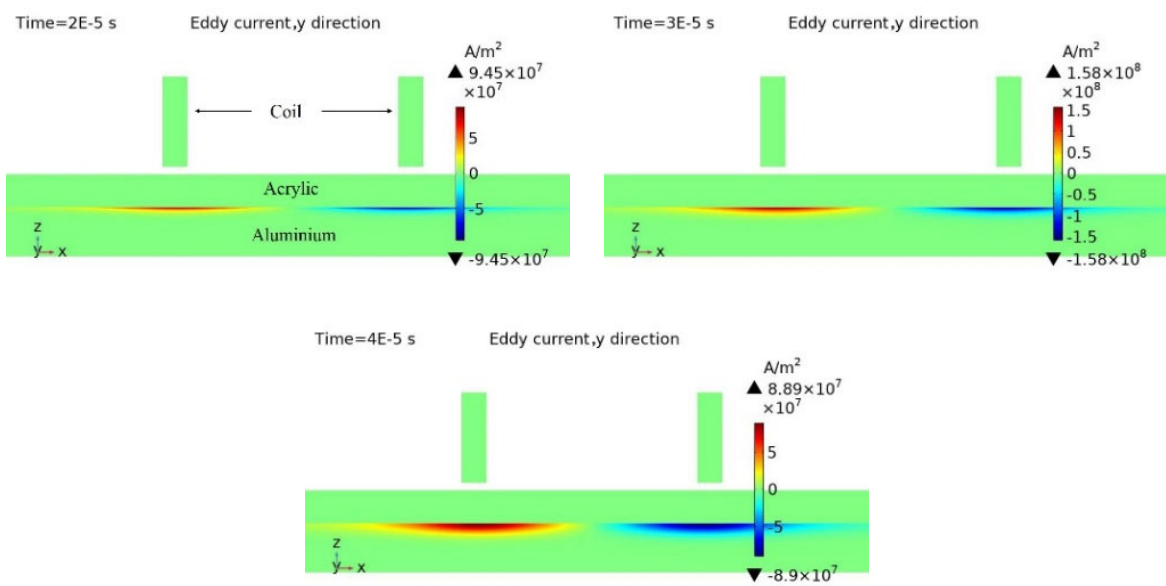

Fig. 4. Eddy current distribution in an acrylic/Al specimen without debonding viewed along the $y$ direction.
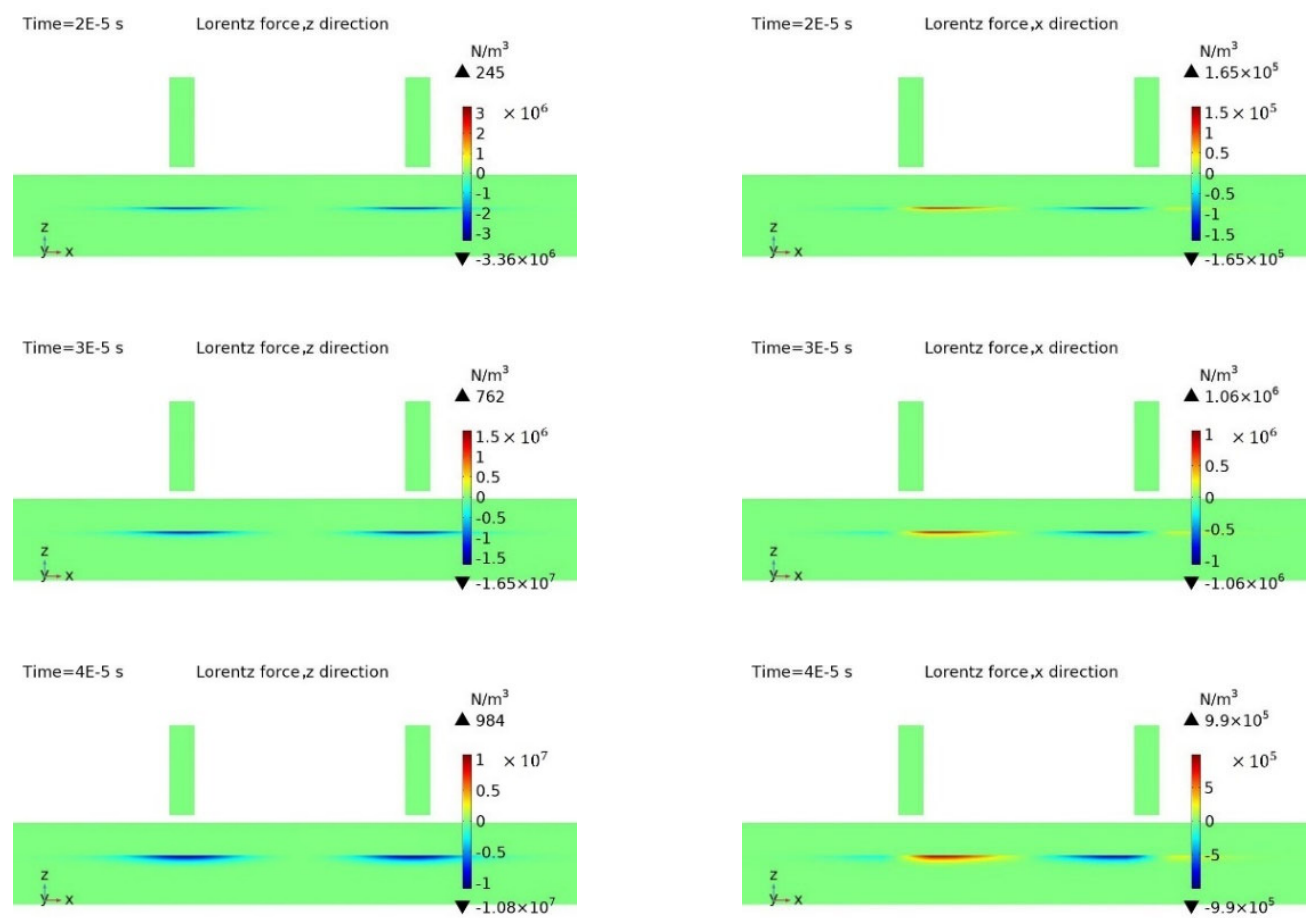
Fig. 5. Lorentz force distributions in an acrylic/Al specimen without debonding viewed along the (a) $z$ and (b) $x$ directions. The values of the arrows on the top and bottom of the color bar are the maximum value of the Lorentz force along the positive and negative $z$ direction.

Figure 6 shows the deformation and wave propagation in the acrylic/Al specimens without and with debonding. Figure 7 shows the A0-mode Lamb wave propagation velocity. It is calculated by using software "Plate Dispersion ver.2" which is able to obtain dispersion curves of guided wave [37]. At low frequencies, the wave velocity varies greatly as the frequency increases. The pulsed guided wave used in this study has a wide frequency band at low frequencies, therefore, the guided wave radiates outward in a ring shape, showing typical guided wave dispersion. Debonding did not strongly affect the propagation of the guided wave; however, at the debonding position, it disrupted the continuity of the guided wave. This is because the guided wave need to pass through two different layers (an upper acrylic layer and lower Al layer) at the same time at the debonding position [38]. Because the layers were separated at this location, the boundary conditions at this location had a sudden change compared with those at adjacent locations. In addition, the superposition of the reflection wave from the surrounding boundary with a direct wave will increase the difficulty of detection. To discuss the effect of debonding on guided wave propagation, three points (P1, P2, and P3) were considered on a circle at a horizontal distance of $200 \mathrm{~mm}$ from the excitation coil, as shown in Fig. 2. P1 with coordinates of $100 \mathrm{~mm}, 0 \mathrm{~mm}, 4 \mathrm{~mm}$ was not on the propagation path through the debonded region. P2 (96 mm, $40 \mathrm{~mm}, 4 \mathrm{~mm})$ was located directly above the debonded region in the specimen with debonding. P3 $(73 \mathrm{~mm}, 100 \mathrm{~mm}, 4 \mathrm{~mm})$ was on the propagation path after passing through debonded region in the specimen with debonding. In the specimen without debonding, P2 and P3 have the same coordinates as those of the debonded specimen. Figure 8 shows the vertical velocity signals of these three points with and without debonding. The signal compared here is the first $200 \mu \mathrm{s}$, because according to Fig. 6, it will be affected by the reflected wave from the boundary after $200 \mu \mathrm{s}$. For the specimen without debonding, the signals at these three points were almost the same, which is because they are located the same distance from the center of the excitation coil and the guided waves propagated uniformly in all directions. However, for the specimen with debonding, the signal at the debonded position (P2) was very different from that of the position without debonding (P1). This is because when the guided wave passes through the upper acrylic material in a region with debonding, the propagation of the guided wave is only 
affected by the physical properties of the acrylic layer as it is not attached to the underlying Al layer. In addition, the signal at P3 after passing through the debonded region was similar to that at P1 where there was no debonding. This is related to the large difference in Young's modulus between $\mathrm{Al}$ and acrylic. In other words, the Al layer plays a leading role in the propagation of guided waves in the specimens. This can be confirmed in Fig. 9, which shows the vertical velocity of three points on the lower Al surface, Q1 (100 mm, $0 \mathrm{~mm},-6 \mathrm{~mm}), \mathrm{Q} 2(96 \mathrm{~mm}, 40 \mathrm{~mm},-6 \mathrm{~mm})$, and -Q3(73 mm, $100 \mathrm{~mm},-6 \mathrm{~mm})$, which correspond to $\mathrm{P} 1, \mathrm{P} 2$, and $\mathrm{P} 3$, respectively, of the specimen with debonding. On the Al surface, the signal is almost unchanged, even at the debonded position.

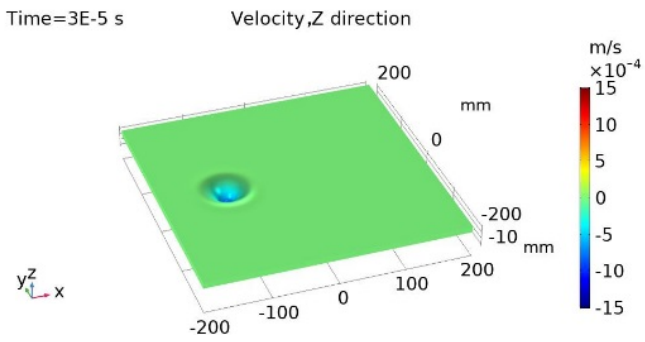

Time $=1 \mathrm{E}-4 \mathrm{~s}$

Velocity, $Z$ direction

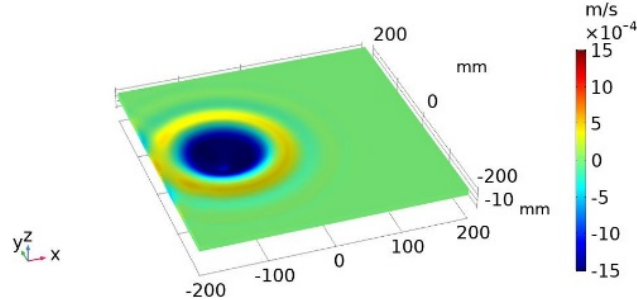

Time $=2 \mathrm{E}-4 \mathrm{~s}$

Velocity, $\mathrm{Z}$ direction

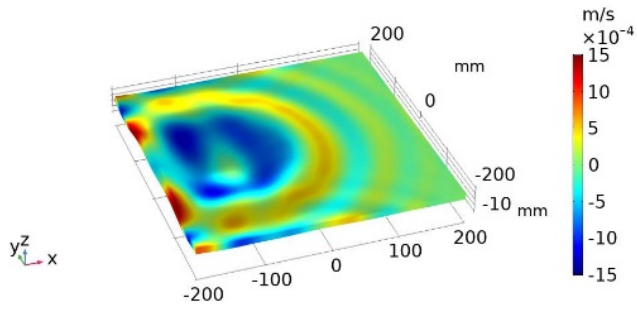

Time $=3 \mathrm{E}-4 \mathrm{~s}$

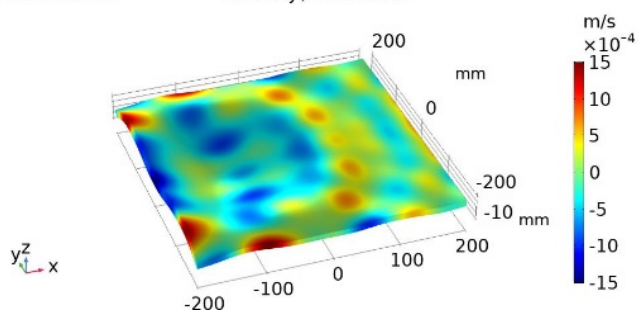

(a)

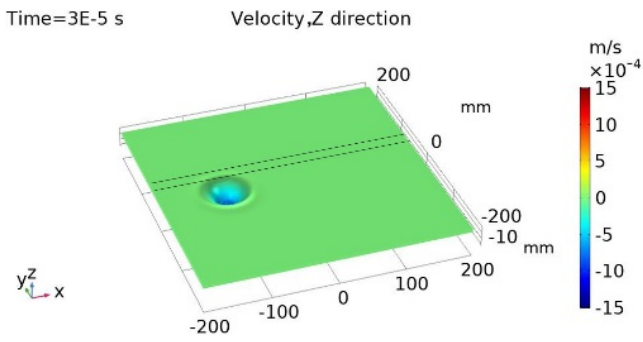

Time $=1 \mathrm{E}-4 \mathrm{~s} \quad$ Velocity, $\mathrm{Z}$ direction

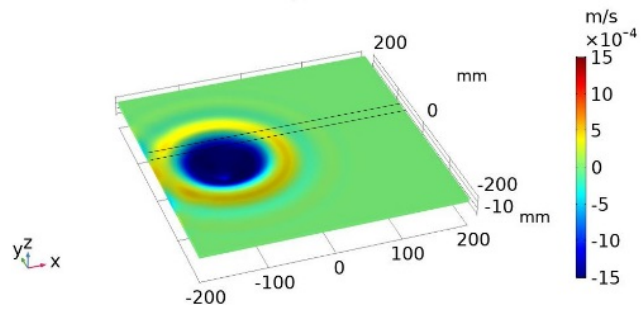

Time $=2 \mathrm{E}-4 \mathrm{~s} \quad$ Velocity, $\mathrm{Z}$ direction

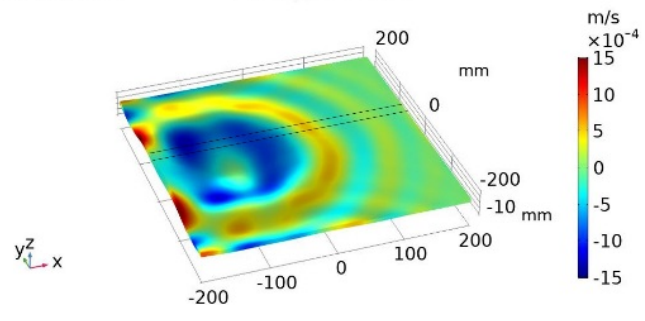

Time $=3 \mathrm{E}-4 \mathrm{~s} \quad$ Velocity, $\mathrm{Z}$ direction

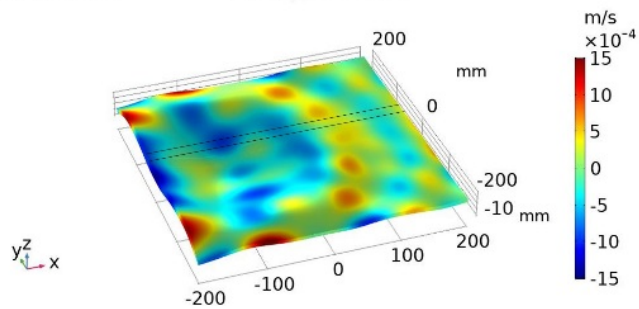

(b) 
Fig. 6 Guided wave propagation in acrylic/Al specimens (deformation and vertical velocity) (a) without and (b) with debonding.

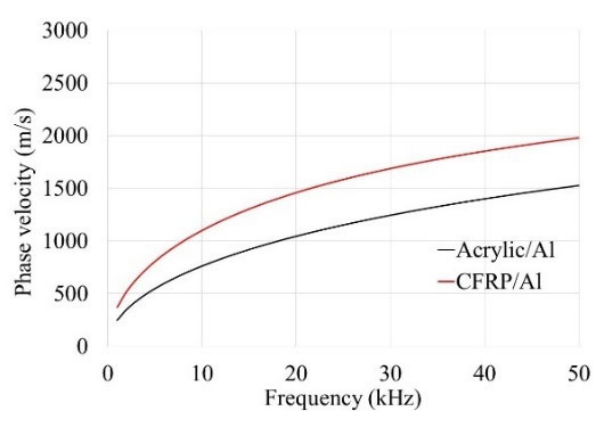

(a)

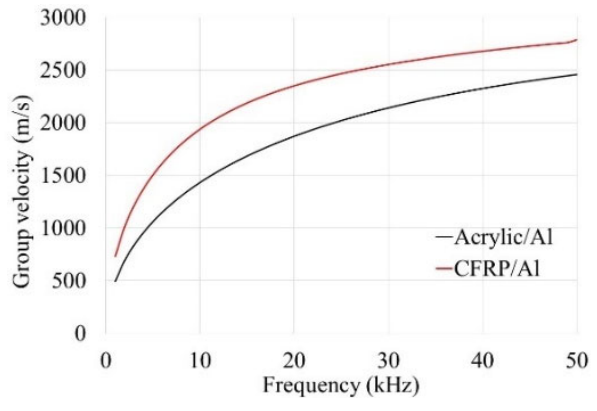

(b)

Fig. 7 A0-mode Lamb wave propagation velocity of acrylic/Al and CFRP/Al specimens. (a) phase velocity and (b) group velocity.

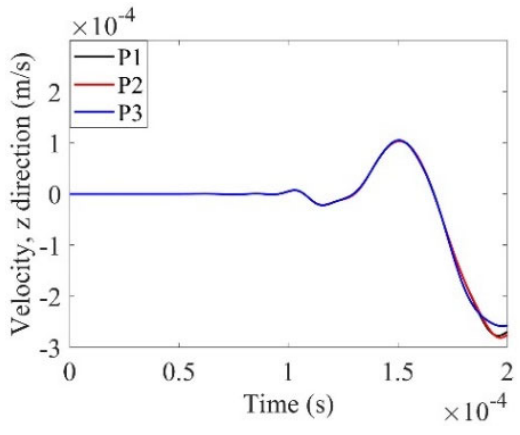

(a)

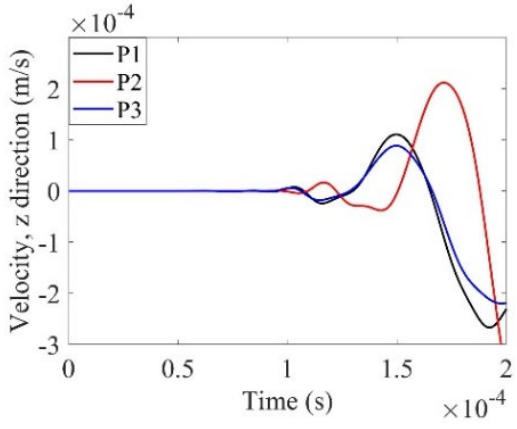

(b)

Fig. 8 Vertical velocity at three points (P1-P3) at a horizontal distance of $200 \mathrm{~mm}$ from the center of the excitation coil for acrylic/Al specimens (a) without and (b) with debonding. P1 (100 mm, 0 mm, 4 mm), P2 (96 mm, $40 \mathrm{~mm}, 4 \mathrm{~mm}), \mathrm{P} 3$ (73 mm, $100 \mathrm{~mm}, 4 \mathrm{~mm})$.

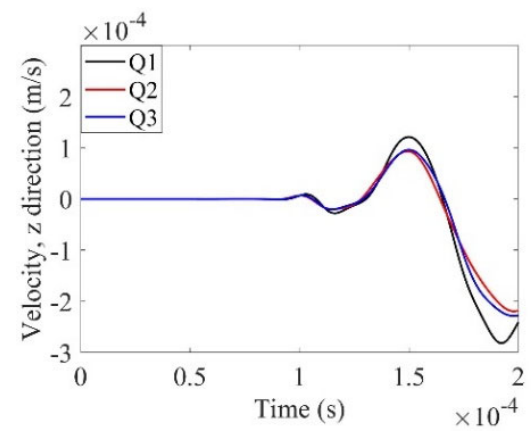


Fig. 9 Vertical velocity of three points (Q1, Q2, and Q3) on the lower surface of acrylic/Al specimen with debonding corresponding to P1, P2, and P3, respectively. Q1 (100 mm, 0 mm, -6 mm), Q2 (96 $\mathrm{mm}, 40 \mathrm{~mm},-6 \mathrm{~mm}), \mathrm{Q} 3(73 \mathrm{~mm}, 100 \mathrm{~mm},-6 \mathrm{~mm})$.

Figure 10 shows the deformation and wave propagation in the CFRP/Al specimens with and without debonding. The CFRP is unidirectional. Unlike the propagation in acrylic/Al specimens, the guided wave radiates outward in the CFRP/Al specimens with an elliptical shape. This is caused by the anisotropy of the CFRP, which has a faster wave velocity along the carbon fiber direction compared with that not along the fiber direction. The A0-mode Lamb wave propagation velocity of CFRP/Al specimen in Fig. 7 is the velocity along the fiber direction, which shows a faster velocity than the acrylic/Al specimen at the same frequency. These specimens also showed typical guided wave dispersion. Guided wave propagation was strongly affected by debonding. The guided wave decelerated at the debonding position. This is also because the guided wave needed to pass through two different layers (upper CFRP and lower Al layers) at the same time at the debonding position. However, because CFRP and acrylic possess considerably different mechanical properties (Young's modulus, directivity, etc.), guided wave propagation in these two materials is very different. As for the acrylic/Al specimens, the reflected waves from the boundary interfered with debonding detection. As with the acrylic/Al specimens, three points (P1, P2, and P3) were considered on a circle at a horizontal distance of $200 \mathrm{~mm}$ from the excitation coil, as shown in Fig. 2. Figure 11 displays the vertical velocity signals at these three points for CFRP/Al specimens with and without debonding. The signals were taken from the first $200 \mu \mathrm{s}$. For the case without debonding, the signals at P1P3 were different. This was caused by the different angles between the wave propagation direction and carbon fiber direction at these positions. The direction of wave propagation to P1 was the same as the carbon fiber direction. The direction of wave propagation to $\mathrm{P} 2$ was about $11.5^{\circ}$ from the carbon fiber direction, and the direction of wave propagation to $\mathrm{P} 3$ was about $30^{\circ}$ from the carbon fiber direction. As the angle between the wave propagation direction and carbon fiber direction increased, the wave velocity decreased rapidly. This can also be seen from the wave propagation in Fig. 10. For the CFRP/Al specimen with debonding, the signals at the debonded position (P2) and after passing through the debonded position (P3) were very different from the signal obtained without passing through the debonding position (P1). Not only is there a time delay between these signals, but this time delay is much larger than that caused by the difference in velocity induced by the difference between the wave propagation direction and carbon fiber 
direction. For point $\mathrm{P} 2$, the interpretation of this time delay is similar to that for the acrylic/Al specimens; it is because the guided wave passes through the upper CFRP layer, which is no longer bound to the underlying Al layer, so the propagation of the guided wave is only affected by the physical properties of the CFRP layer. For the time delay at point P3, it is because the guided waves decelerate in the CFRP and Al layers when they pass through the debonded position, which generates a time delay of the guided wave in the specimen after passing through the debonded region. This is illustrated in Fig. 12. At the debonding position, different to the behavior of the acrylic/Al specimen, the signal on the lower surface of the Al was also delayed. This shows that in the CFRP/Al specimen, Al no longer plays a dominant role in wave propagation; instead, both the CFRP and Al layers are important mechanisms of guided wave propagation.
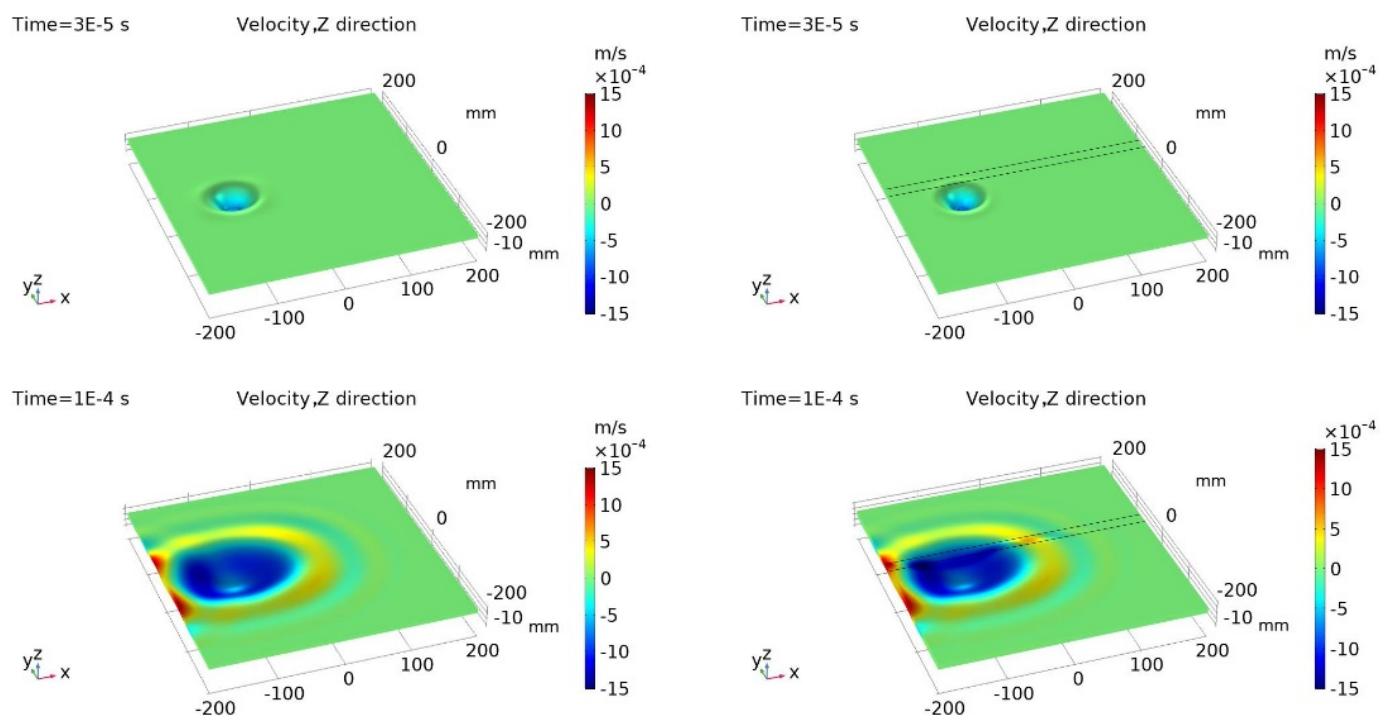

Time $=1.5 \mathrm{E}-4 \mathrm{~s} \quad$ Velocity, $\mathrm{Z}$ direction
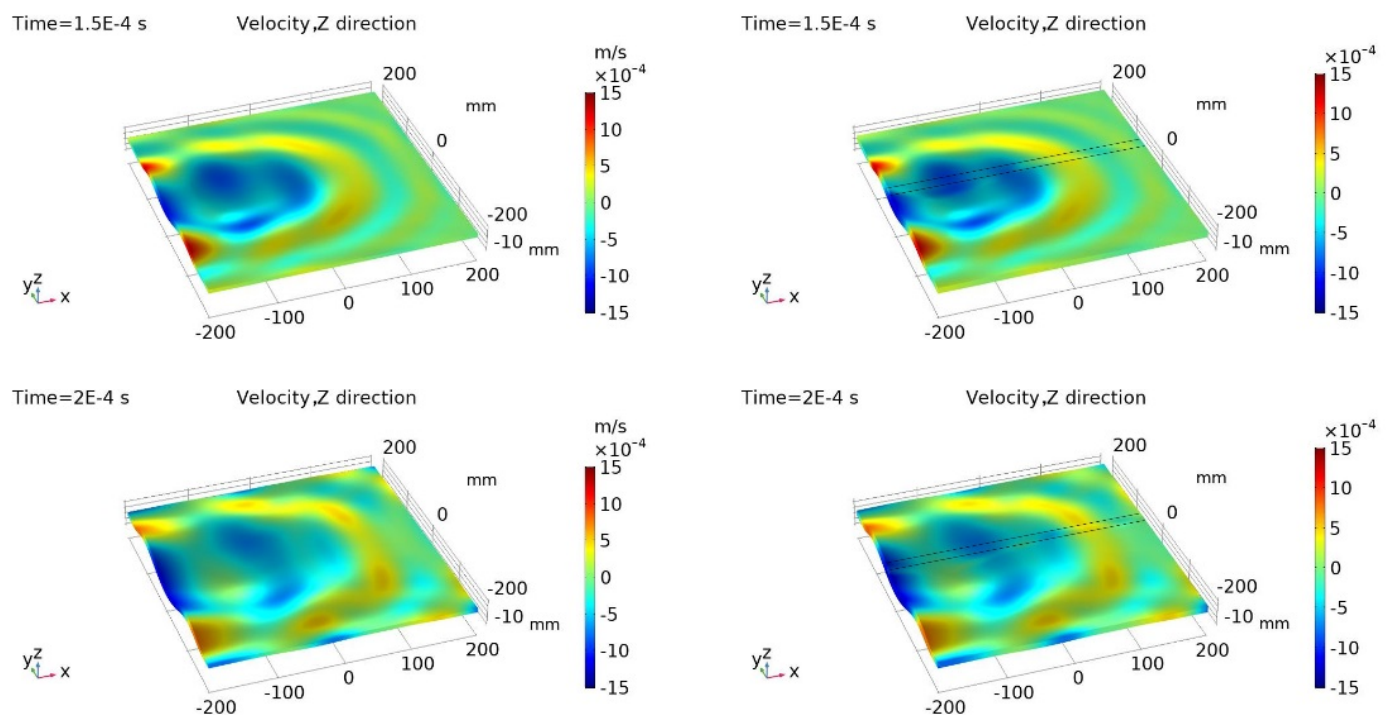


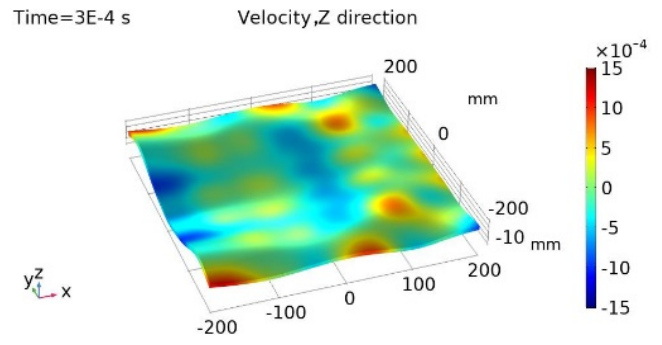

(a)

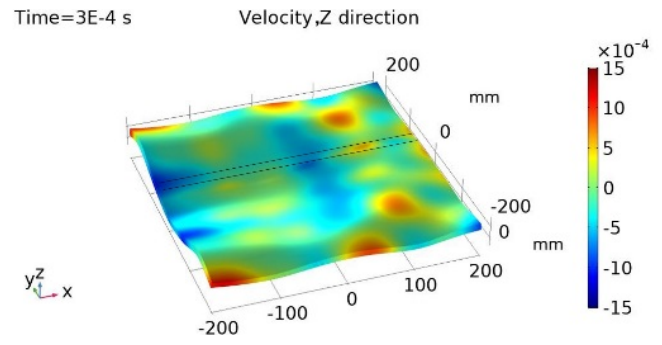

(b)

Fig. 10 Guided wave propagation in CFRP/Al specimens (deformation and vertical velocity) (a) without and (b) with debonding.

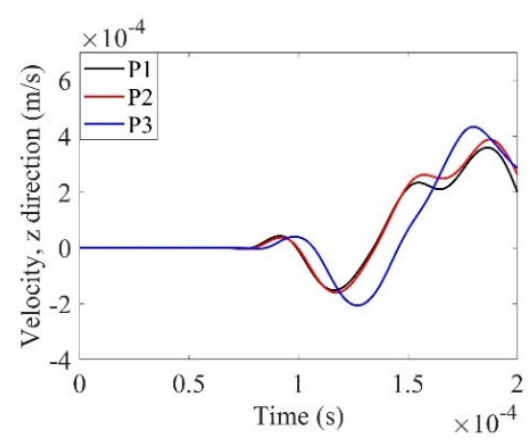

(a)

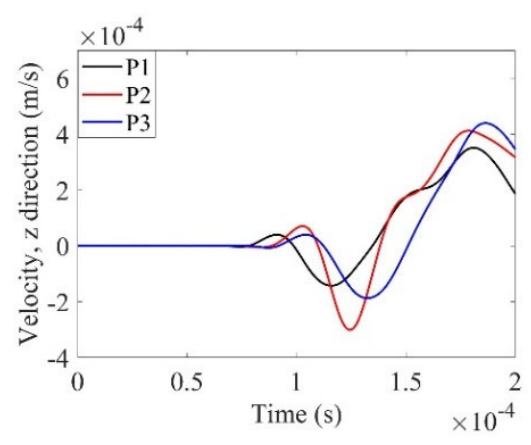

(b)

Fig. 11 Vertical velocity of three points (P1-P3) at a horizontal distance of $200 \mathrm{~mm}$ from the center of the excitation coil for CFRP/Al specimens (a) without and (b) with debonding. P1 (100 mm, $0 \mathrm{~mm}$, $4 \mathrm{~mm}), \mathrm{P} 2$ (96 mm, $40 \mathrm{~mm}, 4 \mathrm{~mm}), \mathrm{P} 3(73 \mathrm{~mm}, 100 \mathrm{~mm}, 4 \mathrm{~mm})$.

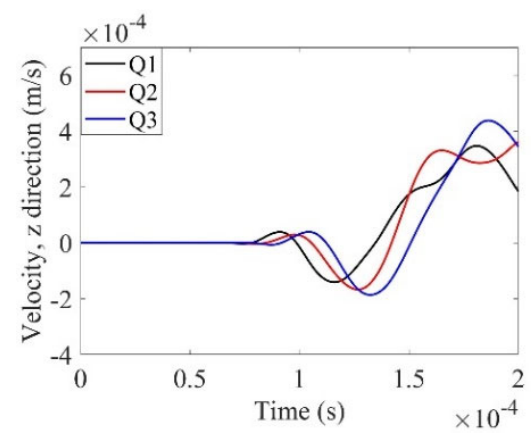

Fig. 12 Vertical velocity of three points (Q1-Q3) corresponding to P1, P2, and P3, respectively, on the lower surface of CFRP/Al specimen with debonding. Q1 (100 mm, $0 \mathrm{~mm},-6 \mathrm{~mm})$, Q2 (96 mm, $40 \mathrm{~mm},-6 \mathrm{~mm}), \mathrm{Q} 3(73 \mathrm{~mm}, 100 \mathrm{~mm},-6 \mathrm{~mm})$.

\section{Experiments}

\subsection{Experimental setup}


The experiment system is shown in Fig. 13. A pulse generator provided a strong pulsed current through the coil. The signal of the guided wave was collected by acoustic emission (AE) sensor (AE-901S, NF Co.) on the upper surface of the specimens. The signal of the AE sensor was amplified by a low-noise wideband preamplifier (NF 9913, NF Co.). Signals were transmitted and received using LabVIEW and its data acquisition board.

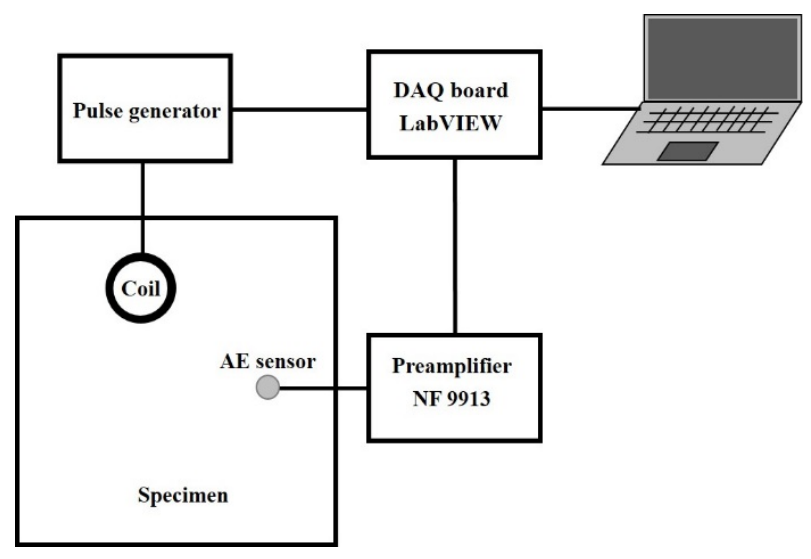

Fig. 13. Schematic of the experiment system for EPAT.

Two groups of adhesive bonding plate specimens were prepared. The materials and dimensions of the specimens were the same as in the simulations, as shown in Fig. 2. The specimens consisted of acrylic/Al alloy (A6061) and CFRP/Al alloy (A6061). The mechanical properties of Al alloy (A6061) are very similar to those of Al in terms of Young's modulus and Poisson's ratio; however, the conductivity of Al alloy is much lower than that of $\mathrm{Al}$ in simulation. However, because the simulation results indicated that the electromagnetic force is concentrated on the upper surface of the metal layer, Al alloy and Al should give similar results except for the absolute value of the wave intensity. Unidirectional CFRP plates are composed of 16 plies of prepregs (P3252S-25, Toray Industries Inc.).

Each group of specimens included one with debonding and one without debonding. To prepare specimens with debonding, releasing agent (Frekote 770-NC, Henkel Japan Ltd.) was painted on the designated debonding area (highlighted in blue in Fig. 2) on both the plastic and Al alloy surfaces. An epoxy adhesive film (AX-2114, Axiom Materials Inc.) was laminated on the Al alloy. The adhesive film was trimmed so that it was not laminated on the debonded area of the specimen. When preparing a specimen without debonding, these procedures were not required. A plastic plate (acrylic or CFRP) was laminated on the adhesive film and then the laminate was covered by a bagging film. The laminates were placed under 
vacuum using a rotary pump and then cured in an autoclave at $50{ }^{\circ} \mathrm{C}$ and $0.8 \mathrm{MPa}$ in a nitrogen atmosphere for $60 \mathrm{~min}$ to give bonded specimens. However, because the epoxy film softened during heating and slightly deformed, epoxy may flow into the designated debonding region. Therefore, it was difficult to ensure that there was complete debonding at the designated debonding position. Figure 14 displays the actual acrylic/Al specimen with debonding. Figure 14(b) and (c) show the actual conditions near measurement point P5 and $\mathrm{P} 2$, respectively.

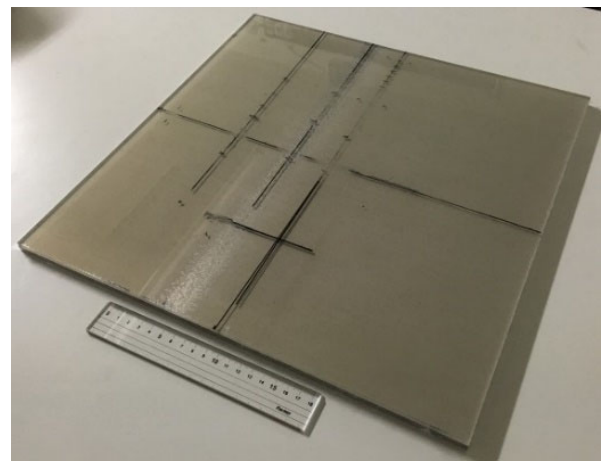

(a)

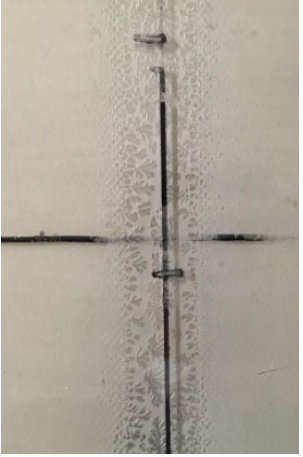

(b)

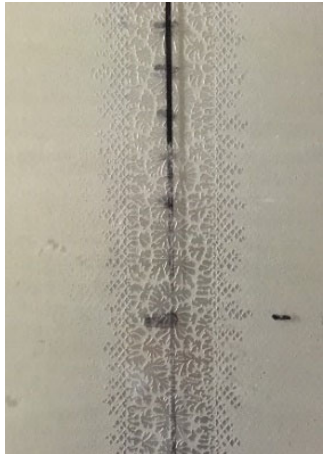

(c)

Fig. 14 Photographs of an acrylic/Al specimen with debonding showing (a) the whole specimen, (b) near the debonding center and P5, and (c) near P2.

The size and position of the excitation coil were the same as those in the simulation. An AE sensor was used to obtain guided wave signals at six points (P1-P6). The measurement points $\mathrm{P} 1-\mathrm{P} 3$ were the same as those in the simulations. P4-P6 were three measurement points at a horizontal distance of $150 \mathrm{~mm}$ from the center of the excitation coil. The pairs $\mathrm{P} 4$ and P1, P5 and P2, and P6 and P3 had the same $y$ coordinates. The AE sensors were attached to the plastic (CFRP or acrylic) surface using double-sided tape. The same pulsed signal was excited in the specimens with and without debonding. Figure 15 shows the waveform of the pulsed current from the monitor, which passed through a 100-kHz low-pass filter. The excitation coil and receiving sensor were located on the plastic composite side and the wave source was the metal layer. Therefore, the EPAT method is suitable for situations where testing is required from the plastic composite side. 


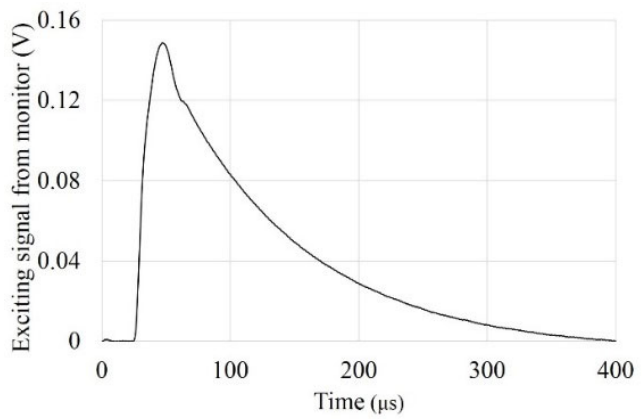

Fig. 15. Pulsed signal form of the monitor in EPAT.

\subsection{Results and discussion}

Figure 16 shows the signals obtained for acrylic/Al specimens at measurement points at a horizontal distance of $200 \mathrm{~mm}$ from the center of the excitation coil. This figure obviously includes reflected signals from the boundary. Here, we are only interested in the signal of the first guided wave as it first passed through a measurement point. As shown in Fig. 17, for the acrylic/Al specimen without debonding, the received signal waveforms at the three measurement points $\mathrm{P} 1-\mathrm{P} 3$ were similar. For the acrylic/A1 specimen with debonding, the received signal waveforms at measurement points P1 and P3 were similar, but they were different from that at P2, which agrees with the results of the corresponding simulation. It should be noted that this does not mean that the experimental and simulation results are exactly the same at any point. In fact, if the simulation and experimental results of each point are compared, they are a little different. There are two main reasons for the difference between simulation and experiment, one is the difference of pulsed excitation, the other is that the attenuation of guided wave propagation is not reflected in the simulation. However, as presented in Fig. 18, the three measurement points P4, P5, and P6 located at a horizontal distance of $150 \mathrm{~mm}$ from the center of the excitation coil showed similar signals for the acrylic/Al specimens with and without debonding, even though P5 is located directly above the designated debonded region. As stated in Section 4.1, although the designated debonded region was a rectangle that ran through the whole specimen, it was difficult to ensure that the obtained specimen was completely debonded at the designated position. In reality, there was only a small area of debonding at the center of the designated debonded area and near point P5, a large area was glued together. There was a large area of actual debonding near P2, although not all debonding was in the designated region. This explains why the signal at point P5 was almost the same as those at points P4 and P6. 


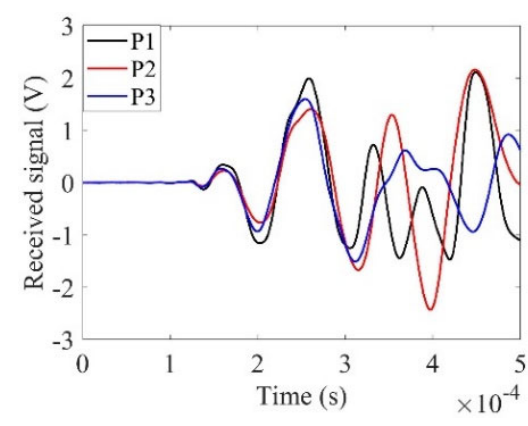

(a)

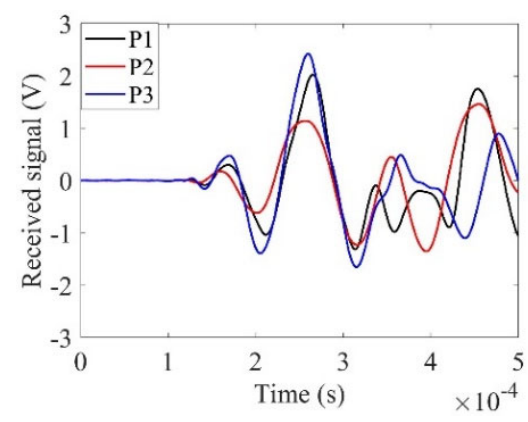

(b)

Fig. 16 Received signals (first $500 \mu \mathrm{s}$ ) at three points (P1-P3) at a horizontal distance of $200 \mathrm{~mm}$ from the center of the excitation coil for acrylic/Al specimens (a) without and (b) with debonding. P1 (100 mm, 0 mm, 4 mm), P2 (96 mm, 40 mm, 4 mm), P3 (73 mm, $100 \mathrm{~mm}, 4 \mathrm{~mm})$.

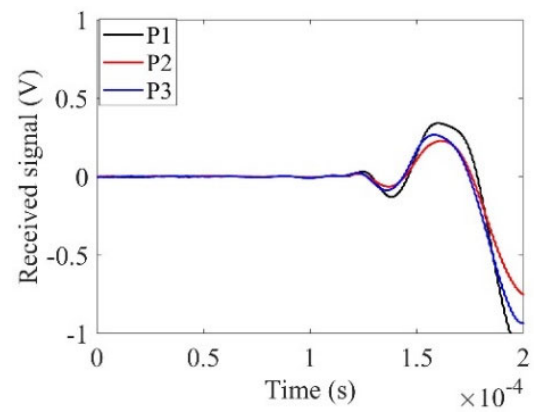

(a)

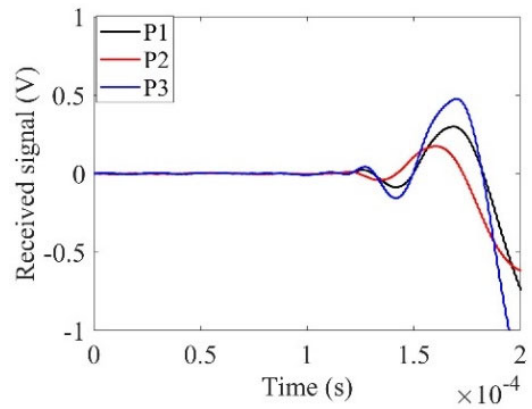

(b)

Fig. 17 Received signals at three points (P1-P3) at a horizontal distance of $200 \mathrm{~mm}$ from the center of the excitation coil for acrylic/Al specimens (a) without and (b) with debonding. P1 $100 \mathrm{~mm}, 0 \mathrm{~mm}$, $4 \mathrm{~mm}), \mathrm{P} 2$ (96 mm, $40 \mathrm{~mm}, 4 \mathrm{~mm}), \mathrm{P} 3$ (73 mm, $100 \mathrm{~mm}, 4 \mathrm{~mm})$.

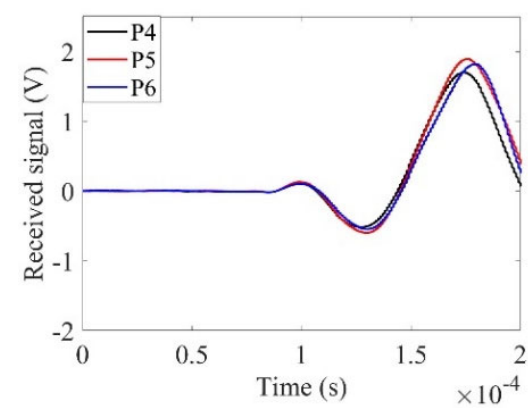

(a)

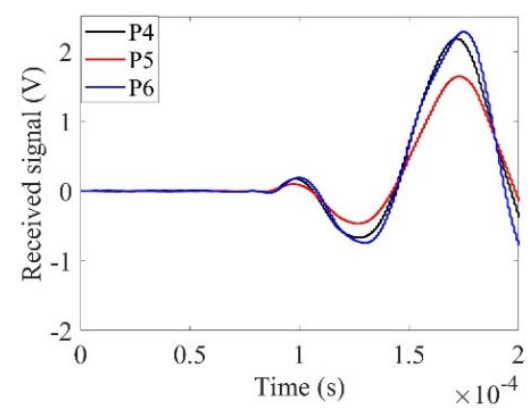

(b) 
Fig. 18 Received signal at three points (P4-P6) at a horizontal distance of $150 \mathrm{~mm}$ from the center of the excitation coil for acrylic/Al specimens (a) without and (b) with debonding. P4 (50 mm, $0 \mathrm{~mm}, 4$ mm), P5 (44 mm, 40 mm, 4 mm), P6 (12 mm, 100 mm, 4 mm).

Figure 19 shows the signals obtained for CFRP/Al specimens at measurement points at a horizontal distance of $200 \mathrm{~mm}$ from the center of the excitation coil. Because of the different wave velocities in different directions in the unidirectional CFRP, the signal at point P3 was received at a later time than those at points P1 and P2. However, the received signal was almost the same for points with or without debonding. This may be because there was no actual debonding in the designated debonded region. Figure 20 shows the signals obtained for CFRP/Al specimens at measurement points at a horizontal distance of $150 \mathrm{~mm}$ from the center of the excitation coil. For the specimen with debonding, the signals at measurement points P5 and P6 showed greater time delays than that of the signal at P4, which is consistent with the simulation results.

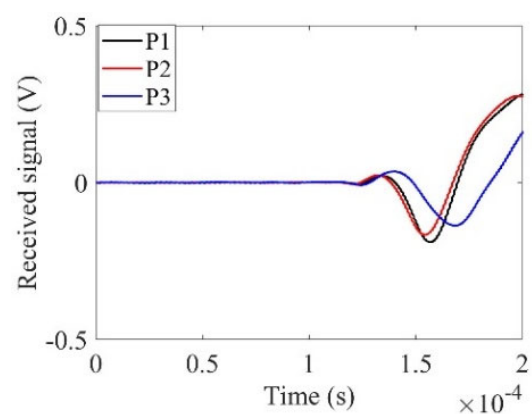

(a)

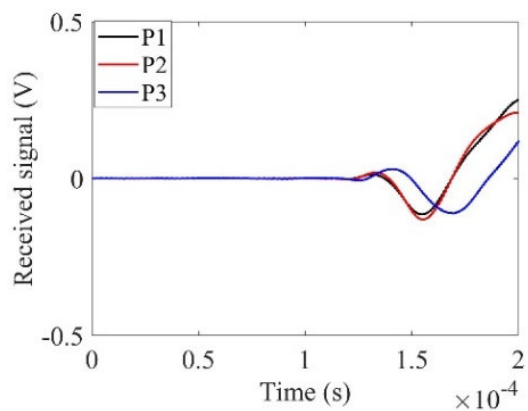

(b)

Fig. 19 Received signal at three points (P1-P3) at a horizontal distance of $200 \mathrm{~mm}$ from the center of the excitation coil for CFRP/Al specimens (a) without and (b) with debonding. P1 (100 mm, $0 \mathrm{~mm}, 4$ mm), P2 (96 mm, 40 mm, 4 mm), P3 (73 mm, 100 mm, 4 mm).

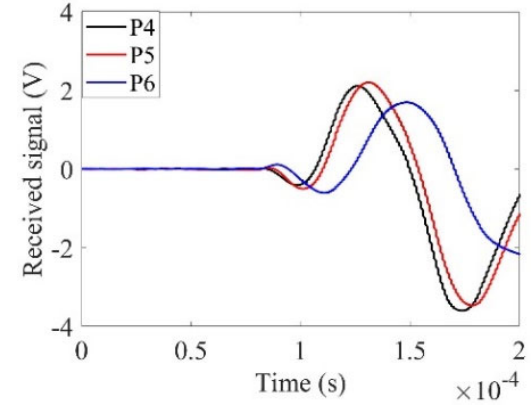

(a)

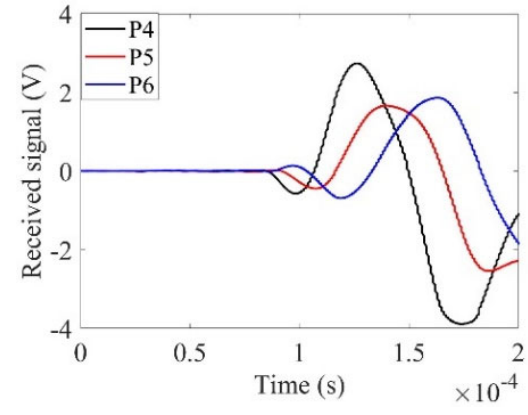

(b) 
Fig. 20 Received signal at three points (P4-P6) at a horizontal distance of $150 \mathrm{~mm}$ from the center of the excitation coil for CFRP/Al specimens (a) without and (b) with debonding. P4 (50 mm, 0 mm, 4 mm), P5 (44 mm, 40 mm, 4 mm), P6 12 mm, 100 mm, 4 mm).

For cases like the acrylic/Al specimens, the mechanical parameters, such as Young's modulus, of the plastic composite layer differ greatly from those of the metal. Thus, debonding can only be detected directly above the debonded region because the physical properties of the metal layer dominate the propagation characteristics of guided waves. Therefore, it is necessary to evaluate the position of debonding by scanning the receiver sensor. However, for cases like the CFRP/Al specimens, the mechanical parameters of the plastic composite layer and metal are fairly similar, so the physical properties of both materials affect the guided wave propagation, and the signals of the guided wave propagation changed after passing through the debonded region. Therefore, in addition to evaluating the position of debonding by scanning the receiver sensor, the position of debonding can also be evaluated by scanning the excitation coil.

\section{Conclusions}

EPAT was used to detect debonding in the adhesive joint of plastic composite/metal adhesive bonding specimens. The EPAT method uses a pulsed excitation current to generate guided waves in specimens without contact, which can be used to detect debonding. FE simulations were performed to analyze wave propagation in acrylic/Al and CFRP/Al specimens. The results showed that the Lorentz force in the $z$ direction was the dominant origin of the generated guided waves. The Lorentz force in the $z$ direction always pointed away from the excitation coil. Therefore, the A0-mode Lamb waves were mainly excited. The guided waves radiated outward in ring and ellipse shapes for the acrylic/Al and CFRP/Al specimens, respectively. The results of FE simulations and experiments showed that when the mechanical parameters of the plastic composite layer differed greatly from those of the metal, such as for the acrylic/Al specimen, debonding could only be detected directly above the debonded region. Therefore, it was necessary to evaluate the position of debonding by scanning the receiver sensor. Conversely, when the mechanical parameters of the plastic composite layer were fairly similar to those of the metal, such as for the CFRP/Al specimen, the debonding position could be evaluated by scanning the receiver sensor or excitation coil.

\section{Acknowledgments}

This work was supported by JKA (Japan Keirin Autorace Foundation) and its promotion funds from Keirin and Auto Race (2019M-161). Part of the work was carried out under the Collaboration Research 
Project of the Institute of Fluid Science, Tohoku University. All the specimens were fabricated with the great help of Dr. Motoi Fujishima (Akita Industrial Technology Center).

\section{REFERENCES}

[1] M.A. Reuter, U.M.J. Boin, A. van Schaik, E. Verhoef, K. Heiskanen, Y, Yang, G. Georgalli, The metrics of material and metal ecology: harmonizing the resource, technology and environmental cycles, Elsevier, 2005.

[2] M. Guo, X. Yi, C. Rudd, X. Liu, Preparation of highly electrically conductive carbon-fiber composites with high interlaminar fracture toughness by using silver-plated interleaves, Composites Science and Technology, 176 (2019), pp. 29-36. DOI: 10.1016/j.compscitech.2019.03.014

[3] Z. Zhang, C. Wang, G. Huang, H. Liu, S. Yang, A. Zhang, Thermal degradation behaviors and reaction mechanism of carbon fibre-epoxy composite from hydrogen tank by TG-FTIR, Journal of hazardous materials, 357 (2018), pp. 73-80. DOI: 10.1016/j.jhazmat.2018.05.057

[4] Y. Zuo, Z. Cao, Y. Cao, Q. Zhang, W. Wang, Dynamic behavior of CFRP/Ti single-lap pinned joints under longitudinal electromagnetic dynamic loading, Composite Structures, 184(2018), pp. 362-371. DOI: 10.1016/j.compstruct.2017.09.079

[5] A. Riccio, P. Linde, A. Raimondo, A. Buompane, A. Sellitto, On the use of selective stitching in stiffened composite panels to prevent skin-stringer debonding, Composites Part B: Engineering, 124 (2017), 64-75. DOI: 10.1016/j.compositesb.2017.05.052

[6] B. Ostré, C. Bouvet, C. Minot, J. Aboissière, Finite element analysis of CFRP laminates subjected to compression after edge impact, Composite Structures, 153 (2016), pp. 478-489. DOI: 10.1016/j.compstruct.2016.06.041

[7] O. Comond, D. Perreux, F. Thiebaud, M. Weber, Methodology to improve the lifetime of type III HP tank with a steel liner, International Journal of Hydrogen Energy, 34(2009), pp. 3077-3090. DOI: 10.1016/j.ijhydene.2009.01.080

[8] F.C. Liu, J. Liao, K. Nakata, Joining of metal to plastic using friction lap welding, Materials \& Design (1980-2015), 54 (2014), pp.236-244. DOI: 10.1016/j.matdes.2013.08.056

[9] J.J.M. Machado, P.D.P. Nunes, E.A.S. Marques, Lucas F.M. da Silva, Adhesive joints using aluminium and CFRP substrates tested at low and high temperatures under quasi-static and impact conditions for the 
automotive industry, Composites Part B: Engineering, 158 (2019), pp. 102-116. DOI: 10.1016/j.compositesb.2018.09.067

[10] V. Tojaga, S. Hazar, S. Östlund, Compressive failure of fiber composites containing stress concentrations: Homogenization with fiber-matrix interfacial decohesion based on a total Lagrangian formulation, Composites Science and Technology, $182 \quad$ (2019), $107758 . \quad$ DOI: 10.1016/j.compscitech.2019.107758

[11] S.T. de Freitas, J. Sinke, Failure analysis of adhesively-bonded skin-to-stiffener joints: Metal-metal vs. composite-metal, Engineering Failure Analysis, 56 (2015), pp. 2-13. DOI: 10.1016/j.engfailanal.2015.05.023

[12] Q. Feng, B. Gao, P. Lu, W.L. Woo, Y. Yang, Y. Fan, X. Qiu, X. Gu, Automatic seeded region growing for thermography debonding detection of CFRP, NDT \& E International, 99 (2018), pp. 36-49. DOI: 10.1016/j.ndteint.2018.06.001

[13] M. Moradi, M.S. Safizadeh, Experimental and numerical study of the effect of using polyurethane instead of Teflon strip to simulate debonding defect in composite patch repairs aluminum plate under thermography inspection, Composites Part B: Engineering, 175 (2019), 107176. DOI: 10.1016/j.compositesb.2019.107176

[14] M. Moradi, M.S. Safizadeh, Edge disbond detection of carbon/epoxy repair patch on aluminum using thermography, Composites Science and Technology, 179 (2019), pp. 41-53. DOI: 10.1016/j.compscitech.2019.04.031

[15] E. Hamed, Z.T. Chang, Effect of creep on the edge debonding failure of FRP strengthened RC beamsA theoretical and experimental study, Composites science and technology, 74 (2013), pp. 186-193. DOI: doi.org/10.1016/j.compscitech.2012.11.011

[16] S.A. Gholizadeh, review of non-destructive testing methods of composite materials, Procedia Structural Integrity, 1 (2016), pp. 50-57. DOI: 10.1016/j.prostr.2016.02.008

[17] R. Ambu, F. Aymerich, F. Ginesu, P.Priolo, Assessment of NDT interferometric techniques for impact damage detection in composite laminates, Composites Science and Technology, 66(2006), pp. 199-205. DOI: 10.1016/j.compscitech.2005.04.027 
[18] F. Liu, Z. Zhou, S. Liu, Y. Yang, L. Zhang, Evaluation of carbon fiber composite repairs using asymmetric-frequency ultrasound waves, Composites Part B: Engineering, 181 (2020), 107534. DOI: 10.1016/j.compositesb.2019.107534

[19] J. Pépin, E. Lainé, J.C. Grandidier, G. Benoit, D. Mellier, M. Weber, C. Langlois, Replication of liner collapse phenomenon observed in hyperbaric type IV hydrogen storage vessel by explosive decompression experiments, International Journal of Hydrogen Energy, 43(2018), pp. 4671-4680. DOI: 10.1016/j.ijhydene.2018.01.022

[20] S.I. Rokhlin, L. Wang, B. Xie, V.A. Yakovlev, L. Adler, Modulated angle beam ultrasonic spectroscopy for evaluation of imperfect interfaces and adhesive bonds, Ultrasonics, 42(2004). pp. 10371047. DOI: $10.1016 /$ j.ultras.2003.12.025

[21] J. Alston, A. Croxford, J. Potter, P. Blanloeuil, Nonlinear non-collinear ultrasonic detection and characterisation of kissing bonds, NDT \& E International, 99 (2018), pp. 105-116. DOI: 10.1016/j.ndteint.2018.07.003.

[22] Q. Yi, G.Y. Tian, B. Yilmaz, H. Malekmohammadi, S. Laureti, M. Ricci, E. Jasiuniene, Evaluation of debonding in CFRP-epoxy adhesive single-lap joints using eddy current pulse-compression thermography, Composites Part B: Engineering, 178 (2019), 107461. DOI: 10.1016/j.compositesb.2019.107461

[23] Cuadra J, Vanniamparambil P A, Hazeli K, et al. Damage quantification in polymer composites using a hybrid NDT approach, Composites Science and Technology, 83 (2013), pp. 11-21. DOI: 10.1016/j.compscitech.2013.04.013

[24] M. Barus, H. Welemane, V. Nassiet, M.L. Pastor, A. Cantarel, F. Collombet, L. Crouzeix, Y.H. Grunevald, NDT-based design of joint material for the detection of bonding defects by infrared thermography, NDT \& E International, 93 (2018), pp. 157-163. DOI: 10.1016/j.ndteint.2017.10.005

[25] S. Yashiro, J. Takatsubo, N. Toyama, An NDT technique for composite structures using visualized Lamb-wave propagation, Composites Science and Technology, 67 (2007), pp. 3202-3208. DOI: 10.1016/j.compscitech.2007.04.006

[26] C. Zhang, Z. Zhang, H. Ji, J. Qiu, C. Tao, Mode conversion behavior of guided wave in glass fiber reinforced polymer with fatigue damage accumulation, Composites Science and Technology, 192 (2020), 108073. DOI: $10.1016 /$ j.compscitech.2020.108073 
[27] K.R. Leonard, M.K. Hinders, Lamb wave tomography of pipe-like structures, Ultrasonics, 43 (2005). pp. 574-583. DOI: $10.1016 /$ j.ultras.2004.12.006

[28] M. Seher, P. Huthwaite, M.J.S. Lowe, Experimental studies of the inspection of areas with restricted access using A0 Lamb wave tomography, IEEE transactions on ultrasonics, ferroelectrics, and frequency control, 63 (2016), pp. 1455-1467. DOI: 10.1109/TUFFC.2016.2583410

[29] N. Hosoya, R. Umino, A. Kanda, I. Kajiwara, A. Yoshinaga, Lamb wave generation using nanosecond laser ablation to detect damage, Journal of Vibration and Control, 24 (2018), pp. 5842-5853. DOI: $10.1177 / 1077546316687904$

[30] K.C. Kang, Y.H. Kim, W.Y. Choi, K.K. Park, Measurement of shallow defects using noncontact broadband leaky Lamb wave produced by pulsed laser with ultrasound microphone, NDT \& E International, 111 (2020), 102224. DOI: 10.1016/j.ndteint.2020.102224

[31] C. Pei, T. Liu, H. Chen, Z. Chen, Inspection of delamination defect in first wall with a flexible EMATscanning system, Fusion Engineering and Design, 136 (2018), pp. 549-553. DOI: 10.1016/j.fusengdes.2018.03.018

[32] C. Pei, S. Zhao, T. Liu, Z. Chen, A new method for plastic strain measurement with Rayleigh wave polarization, Ultrasonics, 88 (2018), pp. 168-173. DOI: 10.1016/j.ultras.2018.04.004

[33] H. Sun, R. Urayama, M. Hashimoto, F. Kojima, T. Uchimoto, T. Takagi, Novel electromagnetic acoustic transducer for measuring the thickness of small specimen areas, International Journal of Applied Electromagnetics and Mechanics, 59 (2019), pp. 1495-1504. DOI: 10.3233/JAE-171106

[34] H. Sun, H. Kosukegawa, M. Hashimoto, T. Uchimoto, T. Takagi, Electromagnetic-pulse-induced acoustic testing for nondestructive testing of plastic composite/metal adhesive bonding, International Journal of Hydrogen Energy, In Press, DOI: 10.1016/j.jhydene.2020.08.079

[35] H. Kosukegawa, Y. Kiso, Y. Yoshikawa, R. Urayama, T. Takagi, Characterization of laminated structure on scarfed slope of CFRP by utilizing eddy current testing with differential type probe, International Journal of Applied Electromagnetics and Mechanics, 59 (2019), pp. 1227-1238. DOI: 10.3233/JAE-171222

[36] J. Cheng, J. Qiu, H. Ji, E. Wang, T. Takagi, T. Uchimoto, Application of low frequency ECT method in noncontact detection and visualization of CFRP material, Composites Part B: Engineering, 110 (2017), pp. 141-152. DOI: 10.1016/j.compositesb.2016.11.018 
[37] http://www-nde.mech.eng.osaka-u.ac.jp/PlatePipeDispersion.htm

[38] V.K. Chillara, B. Ren, C.J. Lissenden, Guided wave mode selection for inhomogeneous elastic waveguides using frequency domain finite element approach, Ultrasonics, 67 (2016), pp. 199-211. DOI:

10.1016/j.ultras.2015.12.007 